\title{
Design and Development of Hand and Foot Contamination Monitor
}

\author{
F. Akter ${ }^{1^{\star}}$, F. Hafiz ${ }^{1}$, M.A.S. Haque ${ }^{1}$, M. Hoq ${ }^{1}$ and M. Hasan ${ }^{2}$ \\ ${ }^{1}$ Institute of Electronics, Atomic Energy Research Establishment, Postcode-1349, Savar, Dhaka, Bangladesh. \\ ${ }^{2}$ Atomic Energy Research Establishment, Postcode-1349, Savar, Dhaka, Bangladesh.
}

\section{ARTICLE INFO}

\section{Article history:}

Received 21 May 2014

Received in revised form 21 August 2014

Accepted 22 August 2014

\section{Keywords:}

Contamination

G-M detector

Microcontroller

PIC12F675

\begin{abstract}
A B S T R A C T
A hand and foot contamination monitor is a health physics instrument to provide detection and measurement of beta-gamma contamination on the palm of each hand and on the bottom surface of both feet/shoes. There are four channels of detection for two hands and two feet. Four G-M detectors have been used in a single unit to cover the whole area of hand and feet. A regulated high voltage DC power supply $(900 \mathrm{~V})$ has been designed using the PIC12F675 microcontroller to operate the pancake Geiger-Müller detectors. The reading is displayed on a linearly scaled $0-100 \mathrm{~Bq} / \mathrm{cm}^{2}$ analog panel meter. The monitor detects beta-gamma radiation emitted by radioactive materials, and if the detected value exceeds a preset level, the monitor sounds an alarm and displays a reading in the respective panel meter. Indicator lamps are used to show the status of contamination. The performance of the system has been tested by using pulse generator and by flat surface radioactive calibration sources. Electronic linearity, detection efficiency, response to the contamination, calibration factor and percentage of error has been measured. Test results were satisfactory and the present system can be used instead of similar imported instruments.
\end{abstract}

\section{INTRODUCTION}

A hand and foot contamination monitor is a health physics instrument to provide detection and measurement of beta-gamma contamination on the palm of each hand and the bottom surface of both feet/shoes. Due to its necessity for radiation protection in the operation of a nuclear facility, a hand and foot monitor has been developed. There are four channels of detection for two hands and two feet. Four G-M detectors are used in a single unit to cover whole area of hands and feet. A high-voltage power supply for those detectors need to be designed by using microcontroller PIC12F675 for low current consumption and better regulation. Care was taken in selecting components and accessories to minimize the cost of the proposed instrument without affecting the sensitivity and quality of the instrument. Moreover this system will be easy to install, operate and maintain.

* Corresponding author.

E-mail address:fpanna@yahoo.com

\section{EXPERIMENTAL METHODS}

\section{Specification}

The specifications of the whole system are shown in Table 1.

Table 1. Specifications of the monitor

\begin{tabular}{ll}
\hline Features & Specification \\
\hline Supply Voltage & $220 \mathrm{~V}, 50 \mathrm{~Hz}$ \\
Detector & Detector Canberra 2000/8767 \\
High Voltage & 900 volts, DC \\
Range \& Scaling & $0-100 \mathrm{~Bq} / \mathrm{cm}^{2}$, linear \\
Display & Analog panel meter \\
Status indicator & $\begin{array}{l}\text { Green light for non-contamination and red } \\
\text { light for contamination }\end{array}$ \\
Alarm setting range & $\begin{array}{l}\text { Alarm can be set at any point within the } \\
\text { full-scale deflection } \\
\text { Alarm display }\end{array}$ \\
Displays lamps and buzzer sound
\end{tabular}

\section{Circuit description}

A hand and foot contamination monitor consists of the following sections: 1) Common Cathode Detector Circuit, 2) Pulse-Shaping Circuit, 3) Synchronizing Circuit, 4) Rectifier and Filtering Circuit, 5) Signal Averaging Circuit, 6) Meter 
Response Circuit, 7) Voltage Reference Circuit, 8) Comparator I and II Circuit, 9) Analog Switch Circuit, 10) Non-Contamination Indicator Circuit, 11) Driver and Contamination Indicator Circuit and 12) Alarm Circuit. The complete block diagram of the hand and foot contamination monitor is shown in Fig 1.

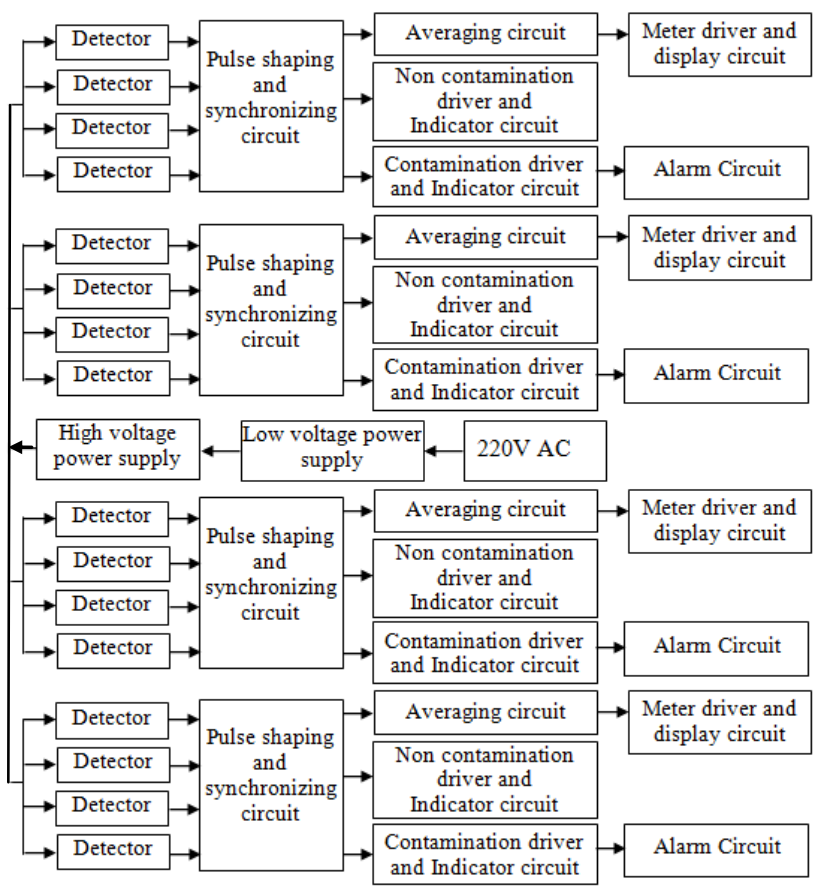

Fig 1. Complete block diagram of hand and foot contamination monitor.

The circuit diagram of the designed hand and foot contamination monitor is shown in Fig. 2 for a single unit. Same circuits have been designed separately for two hands and two feet.

\section{Common cathode detector circuit}

The high-voltage supply of 900 volts is connected to the anode of each detector through resistors $R 1, R 3, R 5$, and $R 7$ respectively. The cathode of each detector is connected to the ground through resistors $R 2, R 4, R 6$, and $R 8$ respectively. When beta or gamma particles enter the detector, the detector conducts and a voltage arises across the cathode resistor. This positive voltage is applied to the triggering input of the respective pulse shaping circuit via resistors $R 9, R 10, R 11$, and $R 12$.

\section{Pulse-shaping and display circuit}

There are four pulse-shaping circuits for four detectors [1]. For detector 1 (GM1) the pulse shaping circuit consists of $C 1, R 9, R 13, V R 1, I C l a$, and $D 1$. Its function is to provide a uniform output for each input pulse regarding of the shape and magnitude. The duration of the high state of the output pulse has been calculated by the equation:

$$
T_{H}=0.2(R 13+V R 1) C 1 \ln (V D D-V S S)
$$

where $V D D=6$ volts and $V S S=0$ volt.

The variable resistor $V R I$ is used to adjust the output pulse width. The remaining three pulse shaping circuits are connected in the same manner with the respective circuits.

\section{Rectifier and filtering circuit}

This circuit consists of $C 5, D 5, R 17, R 18$, and $V R 5$. Diode $D 5$ and capacitor $C 5$ are used to rectify and filter the input signal. Resistors $R 17$ and $R 18$ are used to control the output current, while variable resistor VR5 is used to change the output voltage.

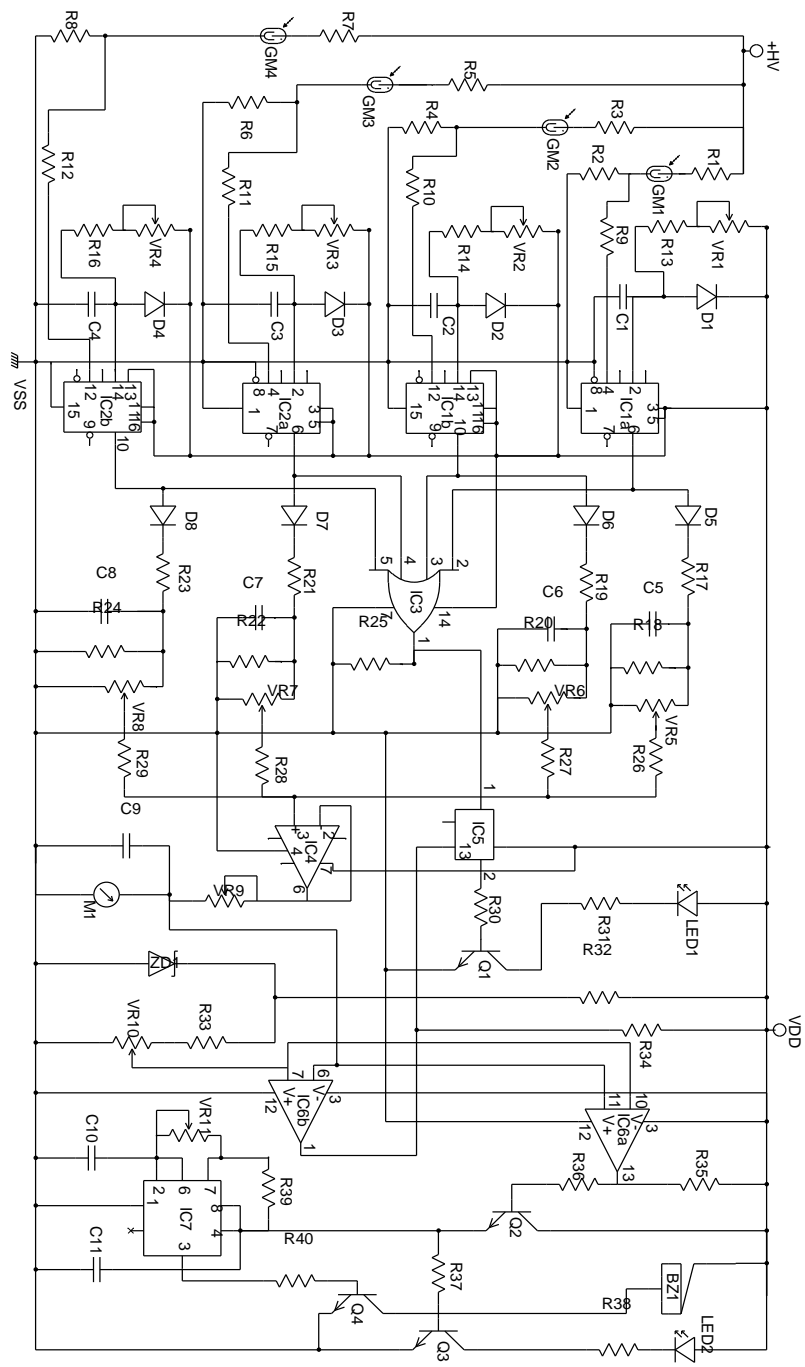

Fig 2. Circuit diagram of a hand and foot contamination monitor (Single unit). 


\section{Synchronizing circuit}

The synchronizing circuit consists of IC 3 and $R 25$. This circuit gives a high output if one or more of its inputs are high. The output pulse of the four pulse-shaping circuits is connected to the input $(2,3,4,5)$ of $I C 3$. If any one input of IC 3 is high then the OR gate output produces a high pulse. This pulse is then fed to pin 1 of IC5; this IC consists of four individual switches capable of controlling either digital or analog signal. The output of IC 3 is fed to the non-contamination indicator circuit.

\section{Averaging circuit}

The noninverting averager consists of $R 26$, $R 27, \quad R 28, \quad R 29$, and IC4 [2]. A four-input noninverting adder is constructed with a passive averager and a voltage follower. A passive averager circuit consists of four equal resistors $R 26, R 27$, $R 28$, and $R 29$, and its inputs are the four voltages to be averaged. The output of the passive averager is $V_{i n}$, where $V_{i n}$ is the average of four input voltage $V 1, V 2, V 3$ and $V 4$ or:

$$
V_{i n}=\frac{V 1+V 2+V 3+V 4}{4}
$$

By connecting a voltage follower to $V_{\text {in }}$ by using $I C 4$, this circuit functions as a noninverting averager. The input voltage $V_{\text {in }}$ is applied directly to the non-inverting (+) input of the IC4 op-amp. Consequently, the output voltage equals the input voltage in both magnitude and sign, i.e., $V_{0}=V_{i n}$.

\section{Meter response circuit}

The meter and time-response circuit consists of variable resistor $V R 9$, meter $M$, and capacitor $C 9$. The variable resistor $V R 9$ is used to calibrate the panel meter in full-scale deflection. The amount of deflection is proportional to the average current flows through the meter. The larger the capacitor, the longer it takes to charge and discharge. Thus, changing the capacitor in the circuit can alter response time.

\section{Analog switch circuit}

The analog switch circuit consists of IC5. The input of the analog switch circuit is connected to the output of the averaging circuit. When the output pin1of $I C 6 b$ is high, control pin 13 of $I C 5$ goes to high, then IC5 acts as a switch; the input pin 1 is connected to the output pin 2 and the non- contamination indicator LED1 indicates green light. The output pin 2 of IC5 is connected to the base of transistor $Q 1$ via resistor $R 30$.

\section{Voltage reference circuit}

The voltage reference circuit consists of $R 32$, R33, VRIO and zener diode ZDI [3]. The highly stable reference voltage of 2.7 volts is derived from the resistor $R 32$ and diode $D Z 1 . R 32$ and $Z D 1$ are connected in series across the 6-volt supply. The resistor $R 33$ and variable resistor $V R 10$ are connected in parallel to the diode $Z D 1$. The voltage across the variable resistor $V R 10$ can be varied from 0 to $180 \mathrm{mV}$. The output of VRIO is connected to the input of pin 10 of IC6a and pin 7 of $I C 6 b$.

\section{Comparator I and II circuit}

The comparator I circuit consists of $R 34$ and $I C 6 b$. The voltage across the meter is applied to the inverting input of the comparator $I C 6 b$, namely pin 6. The fraction of the reference voltage is applied to the non-inverting input pin 7 of IC $6 b$. When the reference voltage is higher than the input voltage, the output of $I C 6 b$ is high. When the reference voltage is less the input voltage, the output of IC $6 b$ is low. The output of $I C 6 b$ is connected to the control pin 13 of IC5.

The comparator II circuit consists of $R 35$ and IC6 $a$. The voltage across the meter is applied to the non-inverting input of the comparator IC6 $a$ pin11. The fraction of the reference voltage is applied to the inverting input of pin 10 of IC6 $a$. When the reference voltage is higher than the input voltage, the output of IC6 $a$ is low. When the reference voltage is less then the input voltage, the output of IC6a is high. The output of $I C 6 a$ is applied to the base of transistor $Q 2$ via resistor $R 36$.

\section{Non-contamination indicator circuit}

This circuit consists of $R 30, R 31, L E D 1$, and transistor $Q 1$. When the control pin 13 of IC5 is high, the input signal on pin 1 of IC5 is connected to the output pin 2 of $I C 5$ and transistor $Q 1$ conducts and turns $L E D 1$ on.

When the control pin 13 of IC5 is low, transistor $Q 1$ does not conduct and LEDI does not emit light. The non-contamination indicator emits light only when the input radiation level is below the threshold level. 


\section{Driver and contamination indicator circuit}

The driver circuit consists of $R 36$ and $Q 2$. The output of emitter follower $Q 2$ is high only when the output pin 13 of IC6a is high. The output of $Q 2$ emitter is connected to the supply pin 8 of IC7 and the base of transistor $Q 3$ through resistor $R 37$. The contamination indicator circuit consists of $R 37$, $R 38, L E D 2$ and $Q 3$. When the output of $Q 2$ is high, transistor $Q 3$ conducts and $L E D 2$ turns on. The red light indicates that the output radiation level exceeds the threshold level.

\section{Alarm circuit}

The circuit consists of R39, R40, VR11, C10, $C 11, Q 4, I C 7$ and buzzer BZ. When the input radiation level exceeds the threshold level, the output of $I C 6 b$ is high and the alarm circuit is activated. IC7 is connected for astable operation. It operates at a frequency determined by $R 39, V R 11$ and C10. The duration of the high state is

$$
T_{H}=0.693(R 39+V R 11) C 10
$$

and the duration of the low state is:

$$
T_{L}=0.693 \mathrm{VR} 11 \mathrm{ClO}
$$

Therefore, the period of the rectangular output is:

$$
T=T_{H}+T_{L}=0.693(R 39+2 \mathrm{VR} 11) C 10
$$

and the frequency is:

$$
f=1 / T=1.44 /(R 39+2 \text { VR11 }) C 10
$$

According to the design requirements the frequency of the astable is $10 \mathrm{~Hz}$. For $R 39=10 \mathrm{k} \Omega$, $V R 11=100 \mathrm{k} \Omega$ and $C 10=680 \mathrm{nF}$, from equations (3) and (4) we obtain $T_{H}=51.83 \mathrm{~ms}$ and $T_{L}=47.124 \mathrm{~ms}$ Hence, the period of the rectangular wave is

$T=T_{H}+T_{L}=51.83 \mathrm{~ms}+47.124 \mathrm{~ms}=98.954 \mathrm{~ms}$ and the frequency is $\mathrm{f}=10.1 \mathrm{~Hz}$

The output pin 3 of IC7 is connected to the base of $Q 4$ through the resistor $R 40$. The collector of $Q 4$ is connected to the 6 volt supply through the buzzer (BZ). When output of the comparator II circuit goes to high, transistor $Q 2$ conducts and the alarm circuit is activated.

\section{Calibration}

The developed system uses four adjacent thin-walled pancake Geiger-Müller detectors for a single zone (here, the term "zone" refers to a hand or foot whose radiation is being measured). Therefore, a total of sixteen detectors are used for the four zones. Electronic linearity, detection efficiency, response to the contamination and calibration factor were measured [4]. Large-area calibration sources of $15 \times 10 \mathrm{~cm}^{2}$ active dimensions were used repeatedly to calibrate the contamination monitor [5]. Radiation sources (Eckert \& Ziegler isotope products) properties are mentioned in Table 2.

Using the equation

$$
A=A_{0} e^{-\lambda}
$$

the final activities of the radionuclides were calculated.

Here, $A_{0}=$ is the initial activity of the source $A=$ is the final activity of the source

\begin{tabular}{|c|c|c|c|c|}
\hline Sources & $\begin{array}{l}\text { Carbon-14 } \\
(\mathrm{C}-14)\end{array}$ & $\begin{array}{l}\text { Chlorine-36 } \\
(\mathrm{Cl}-36)\end{array}$ & $\begin{array}{l}6 \text { Strontium-90 } \\
(\text { Sr-90) }\end{array}$ & $\begin{array}{l}\text { Americium- } \\
241 \text { (Am-241) }\end{array}$ \\
\hline $\begin{array}{l}\text { Initial Activity } \\
\left(A_{0}\right) \mathrm{KBq}\end{array}$ & 3.008 & 2.997 & 3.020 & 2.490 \\
\hline $\begin{array}{l}\text { Reference date, } \\
\text { (Nov 2009) }\end{array}$ & 1 & 1 & 1 & 15 \\
\hline $\begin{array}{l}\text { Final Activity } \\
\text { (A) } \mathrm{KBq}\end{array}$ & 3.00702 & 2.9969 & 2.8316 & 2.479 \\
\hline $\begin{array}{l}\text { Measurement } \\
\text { date } \\
\text { (July 2012) }\end{array}$ & 4 & 4 & 4 & 4 \\
\hline $\begin{array}{l}\text { Active } \\
\text { dimensions }\left(\mathrm{cm}^{2}\right)\end{array}$ & 150 & 150 & 150 & 150 \\
\hline $\begin{array}{l}\text { Half-life }\left(\mathrm{T}_{1 / 2}\right) \\
(y)\end{array}$ & 5730 & 301000 & 28.8 & 432 \\
\hline $\begin{array}{l}\text { Energy }(\mathrm{MeV}) \\
(\max )\end{array}$ & $\begin{array}{l}\text { Beta } \\
0.156\end{array}$ & $\begin{array}{l}\text { Beta } \\
0.714\end{array}$ & $\begin{array}{c}\text { Beta } \\
2.284\end{array}$ & $\begin{array}{l}\text { Alpha } 5.49 \\
\quad(85 \%) \\
\text { Gamma } 0.059 \\
(36 \%) \\
\end{array}$ \\
\hline
\end{tabular}
$\lambda=$ the decay constant $=\frac{0.693}{T_{1 / 2}}$ (where $T_{1 / 2}=$ half life) $t=$ the amount of time elapsed from $A_{0}$ to $A$.

Table 2. Properties of sources

As the first step of calibration, it was checked to ensure that the meter is mechanically zero, the audio indicator is working, and the high voltage supply is being generated. An electronic pulse generator (Model TTi-TG215) was used to input pulses at a known rate into the contamination monitor. Then the meter response was adjusted to accurately reflect the incoming pulse rate, and other control circuits were also tested.

In this calibration, three sources $(\mathrm{C}-14, \mathrm{Cl}-36$, and $\mathrm{Sr}-90)$ were employed. Those sources emitted beta particles over a range of energy from the lowest energy to some maximum energy. Am-241 sources were used to measure the gamma contamination of the monitor. 


\section{Instrument response to beta contamination}

The instrument reading have been determined with placing the calibration source of known emission rate concentrically above the detector position, at a source close to the detector and the instrument response have been calculated [4].

\section{Calculation for instrument response}

Table 3 (a-d) show the meter reading (cps) for four different zone by using different calibration sources.

Table 3 (a). Meter reading (cps) (for left hand)

\begin{tabular}{ccccc}
\hline $\begin{array}{c}\text { No of } \\
\text { Obs. }\end{array}$ & $\begin{array}{c}\text { For } \\
\text { C-14 }\end{array}$ & $\begin{array}{c}\text { For } \\
\text { Cl-36 }\end{array}$ & $\begin{array}{c}\text { For } \\
\text { Sr-90 }\end{array}$ & $\begin{array}{c}\text { For } \\
\text { Am- } \\
241\end{array}$ \\
\hline 1 & 60 & 315 & 637.5 & 285 \\
2 & 75 & 300 & 690 & 300 \\
3 & 67.5 & 330 & 705 & 330 \\
4 & 60 & 322.5 & 735 & 330 \\
5 & 67.5 & 300 & 750 & 270 \\
6 & 60 & 270 & 675 & 300 \\
7 & 75 & 330 & 705 & 240 \\
8 & 67.5 & 360 & 750 & 255 \\
9 & 60 & 330 & 675 & 300 \\
10 & 60 & 345 & 735 & 330 \\
11 & 65.25 & 285 & 720 & 285 \\
12 & 67.5 & 300 & 675 & 300 \\
Avg & 65.44 & 315.6 & 704.4 & 293.75 \\
\hline
\end{tabular}

Table 3 (b). Meter reading (cps) (for right hand)

\begin{tabular}{ccccc}
\hline $\begin{array}{r}\text { No of } \\
\text { Obs. }\end{array}$ & $\begin{array}{c}\text { For } \\
\text { C-14 }\end{array}$ & $\begin{array}{c}\text { For } \\
\text { Cl-36 }\end{array}$ & $\begin{array}{c}\text { For } \\
\text { Sr-90 }\end{array}$ & $\begin{array}{c}\text { For } \\
\text { Am- } \\
241\end{array}$ \\
\hline 1 & 60 & 300 & 750 & 225 \\
2 & 75 & 315 & 780 & 255 \\
3 & 60 & 352.5 & 720 & 330 \\
4 & 75 & 330 & 735 & 300 \\
5 & 45 & 375 & 735 & 240 \\
6 & 75 & 307.5 & 675 & 285 \\
7 & 60 & 300 & 750 & 300 \\
8 & 67.5 & 322.5 & 787.5 & 300 \\
9 & 60 & 345 & 787.5 & 270 \\
10 & 75 & 330 & 787.5 & 285 \\
11 & 75 & 315 & 735 & 270 \\
12 & 45 & 285 & 720 & 300 \\
Avg & 64.38 & 323.1 & 746.9 & 280
\end{tabular}

Table 3 (c). Meter reading (cps) (for left foot)

\begin{tabular}{ccccc}
\hline $\begin{array}{c}\text { No of } \\
\text { Obs. }\end{array}$ & $\begin{array}{c}\text { For } \\
\text { C-14 }\end{array}$ & $\begin{array}{c}\text { For } \\
\text { Cl-36 }\end{array}$ & $\begin{array}{c}\text { For } \\
\text { Sr-90 }\end{array}$ & $\begin{array}{c}\text { For } \\
\text { Am-241 }\end{array}$ \\
\hline 1 & 60 & 285 & 787.5 & 330 \\
2 & 45 & 315 & 750 & 300 \\
3 & 60 & 300 & 825 & 240 \\
4 & 75 & 307.5 & 750 & 255 \\
5 & 60 & 315 & 780 & 210 \\
6 & 60 & 360 & 720 & 240 \\
7 & 75 & 300 & 735 & 210 \\
8 & 75 & 270 & 780 & 225 \\
9 & 60 & 270 & 735 & 240 \\
10 & 75 & 345 & 750 & 255 \\
11 & 60 & 315 & 705 & 270 \\
12 & 75 & 300 & 750 & 285 \\
Avg & 65 & 306.9 & 755.6 & 255 \\
\hline
\end{tabular}

Table 3 (d). Meter reading (cps) (for right foot)

\begin{tabular}{ccccc}
\hline $\begin{array}{c}\text { No of } \\
\text { Obs. }\end{array}$ & $\begin{array}{c}\text { For } \\
\text { C-14 }\end{array}$ & $\begin{array}{c}\text { For } \\
\text { Cl-36 }\end{array}$ & $\begin{array}{c}\text { For } \\
\text { Sr-90 }\end{array}$ & $\begin{array}{c}\text { For } \\
\text { Am-241 }\end{array}$ \\
\hline 1 & 75 & 330 & 787.5 & 225 \\
2 & 75 & 315 & 825 & 210 \\
3 & 67.5 & 292.5 & 750 & 240 \\
4 & 75 & 285 & 780 & 210 \\
5 & 60 & 367.5 & 720 & 240 \\
6 & 75 & 375 & 735 & 225 \\
7 & 60 & 322.5 & 780 & 270 \\
8 & 60 & 337.5 & 735 & 255 \\
9 & 60 & 315 & 675 & 255 \\
10 & 75 & 330 & 735 & 225 \\
11 & 52.5 & 300 & 750 & 240 \\
12 & 7.5 & 285 & 720 & 255 \\
Avg & 61.88 & 321.3 & 749.4 & 237.5 \\
\hline
\end{tabular}

The Instrument Response has been measured according to the equation (8):

$$
\text { Instrument Response }=\frac{R-B}{S E R}
$$

where, $R$ is the observed reading $\left(\mathrm{s}^{-1}\right), B$ is the background count rate $\left(\mathrm{s}^{-1}\right), S E R$ is the surface emission rate per unit area of the source $\left(\mathrm{s}^{-1} \mathrm{~cm}^{-2}\right)$. Consider the effects of background count rate $\left(\mathrm{s}^{-1}\right)$, $S E R$ is the surface emission rate per unit area of the source $\left(\mathrm{s}^{-1} \mathrm{~cm}^{-2}\right)$. Consider the effects of a background count rate of $0.5 \mathrm{cps}$ [6]. The surface 
emission rate per unit area of different sources was calculated by using the equation:

$$
S E R=\frac{A}{D}
$$

where $A$ is the final activity of the source and $D$ is the active dimension of the source.

From the data in Table 3 and using equations (8) and (9), SER and the Instrument Response for left hand, right hand, left foot and right foot are found; those are shown in Table 4.

Table 4. Summary of Instrument Response

\begin{tabular}{|c|c|c|c|c|c|c|c|c|c|}
\hline \multirow{3}{*}{$\begin{array}{l}\text { Radio- } \\
\text { Nuclide }\end{array}$} & \multirow{3}{*}{$\begin{array}{c}S E R \\
\left(\mathrm{~Bq} / \mathrm{cm}^{2}\right)\end{array}$} & \multicolumn{4}{|c|}{$\begin{array}{c}\text { Observed meter reading } \\
R(\mathrm{cps})\end{array}$} & \multicolumn{4}{|c|}{$\begin{array}{l}\text { Instrument response } \\
\quad\left(\mathrm{cps} / \mathrm{Bq} / \mathrm{cm}^{2}\right)\end{array}$} \\
\hline & & Left & Right & Left & Right & Left & Right & Left & Right \\
\hline & & Hand & Hand & Foot & Foot & Hand & Hand & Foot & Foot \\
\hline C-14 & 20 & 65.43 & 64.37 & 65 & 61.87 & 3.24 & 3.19 & 3.22 & 3.06 \\
\hline Cl-36 & 19.96 & 315.62 & 323.12 & 306.87 & 321.25 & 15.78 & 16.16 & 15.34 & 16.06 \\
\hline $\mathrm{Sr}-90$ & 18.87 & 704.37 & 746.87 & 755.62 & 749.37 & 37.30 & 39.55 & 40.01 & 39.68 \\
\hline \multirow[t]{2}{*}{ Am-241 } & 16.52 & 293.75 & 280 & 255 & 237.5 & 17.75 & 16.91 & 15.40 & 14.34 \\
\hline & & & & & & & \multicolumn{3}{|c|}{ Background $0.5 \mathrm{cps}$} \\
\hline
\end{tabular}

\section{Instrument detection efficiency}

Efficiency is the number of ionization events or "counts" the detector registers for each actual disintegration that occurs in the source, and is expressed as a fraction of counts per disintegration [7]. Efficiencies for the detector are dependent on the type and energy of the radiation. Efficiency is determined as shown in equation:

Efficiency

$$
\varepsilon=\frac{\text { cpm }_{\text {source }}-\text { cpm }_{\text {background }}}{\text { dpm }_{\text {source }}} \times 100
$$

Consider the effects of background radiation. The total surface emission rate of source for detector area can be determined by the equation:

$$
d p s_{\text {source }}=\frac{A \times W}{D}
$$

where $A$ is the final activity of the source, $W$ is the sensitive total detector area, and $D$ is the active dimension of the source.

The area of the detector

$$
W=\pi r^{2}
$$

where $\mathrm{r}$ is the radius of the detector

$$
\text { So, } W=\pi \times(2.225)^{2}=15.553 \mathrm{~cm}^{2}
$$

Area of four detectors $=4 \times 15.553=62.212 \mathrm{~cm}^{2}$. The detection efficiency for left hand, right hand, left foot and right foot as obtained using equations (10) and (11) from the data in Table 4 are shown in Table 5.
Table 5. Summary of Detection Efficiency

\begin{tabular}{cccccccccc}
\hline \multirow{2}{*}{$\begin{array}{c}\text { Radio- } \\
\text { Nuclide }\end{array}$} & $\begin{array}{c}\text { Source } \\
\text { (dpm) }\end{array}$ & $\begin{array}{c}\text { Left } \\
\text { Hand }\end{array}$ & $\begin{array}{c}\text { Right } \\
\text { Hand }\end{array}$ & $\begin{array}{c}\text { Left } \\
\text { Foot }\end{array}$ & $\begin{array}{c}\text { Right } \\
\text { Foot }\end{array}$ & $\begin{array}{c}\text { Left } \\
\text { Hand }\end{array}$ & $\begin{array}{c}\text { Right } \\
\text { Hand }\end{array}$ & $\begin{array}{c}\text { Left } \\
\text { Foot }\end{array}$ & $\begin{array}{c}\text { Right } \\
\text { Foot }\end{array}$ \\
\hline C-14 & 74820 & 3925.8 & 3862.2 & 3900 & 3712.2 & 5.20 & 5.12 & 5.17 & 4.92 \\
Cl-36 & 74520 & 18937.2 & 19387.2 & 18412.2 & 19275 & 25.37 & 25.97 & 24.66 & 25.82 \\
Sr-90 & 70440 & 42262.244812 .245337 .2 & 44962.2 & 59.95 & 63.57 & 64.32 & 63.78 \\
Am-241 & 61680 & 17625 & 16800 & 15300 & 14250 & 28.52 & 27.18 & 24.75 & 23.05 \\
\hline \multicolumn{1}{c}{} & & & & & \multicolumn{4}{c}{ Background $0.5 \mathrm{cps}$} \\
\hline
\end{tabular}

\section{Calibration factor}

The instrument's reading indicates the measured activities per unit area in units of $\mathrm{Bq} / \mathrm{cm}^{2}$. The values are calculated by multiplying measured net counting rates with a nuclide-specific calibration factor according to the equation: Measured activity

$$
A=C_{F} \times \text { Observed reading }
$$

The calibration factor $\left(C_{F}\right)$ of a surface contamination instrument is given by the ratio of the certified surface emission rate per unit area of the source divided by the instrument net reading [8]. The calibration factor can be measured by the following equation:

$$
C_{F}=\frac{S E R}{M-M b}
$$

where $S E R$ is the surface emission rate per unit area for the radionuclide source (in units of $\mathrm{Bq} / \mathrm{cm}^{2}$ ),$M$ is the monitor count rate $\left(\mathrm{Bq} / \mathrm{cm}^{2}\right)$ when exposed to

\begin{tabular}{|c|c|c|c|c|c|c|c|c|c|}
\hline \multirow{2}{*}{$\begin{array}{l}\text { Radio- } \\
\text { Nuclide }\end{array}$} & \multirow{2}{*}{$\begin{array}{c}\text { Reference } \\
\text { Detection } \\
\text { Efficiency } \\
\quad(\%)\end{array}$} & \multicolumn{4}{|c|}{$\begin{array}{c}\text { Measured Detection } \\
\text { Efficiency }(\%)\end{array}$} & \multicolumn{4}{|c|}{ Measured Calibration factor } \\
\hline & & $\begin{array}{l}\text { Left } \\
\text { Hand }\end{array}$ & $\begin{array}{l}\text { Right } \\
\text { Hand }\end{array}$ & $\begin{array}{l}\text { Left } \\
\text { Foot }\end{array}$ & $\begin{array}{l}\text { Right } \\
\text { Foot }\end{array}$ & $\begin{array}{l}\text { Left } \\
\text { Hand }\end{array}$ & $\begin{array}{l}\text { Right } \\
\text { Hand }\end{array}$ & $\begin{array}{l}\text { Left } \\
\text { Foot }\end{array}$ & $\begin{array}{l}\text { Right } \\
\text { Foot }\end{array}$ \\
\hline C-14 & $4-6$ & 5.20 & 5.20 & 5.17 & 4.92 & 5 & 4.44 & 5.26 & 5.52 \\
\hline $\mathrm{Cl}-36$ & $21-26$ & 25.37 & 25.97 & 24.66 & 25.82 & 0.97 & 0.94 & 1.00 & 0.95 \\
\hline Sr-90 & $55-60$ & 59.95 & 63.57 & 64.32 & 63.78 & 0.40 & 0.45 & 0.38 & 0.38 \\
\hline Am-241 & 25 & 28.52 & 27.18 & 24.75 & 23.05 & 0.86 & 1.22 & 1.00 & 1.07 \\
\hline
\end{tabular}
the calibration source at a specified distance, and $M b$ is the monitor background count rate $\left(\mathrm{Bq} / \mathrm{cm}^{2}\right)$. The calibration factor for left hand, right hand, left foot and right foot found using equation (14) are shown in table 6 .

Table 6. Detection Efficiency $(\varepsilon)$ and Calibration factor $\left(C_{F}\right)$

\section{RESULTS AND DISCUSSION}

Table 6 represents the detection efficiency $(\varepsilon)$ and calibration factor $(C F)$ of the instrument. It shows that the measured detection efficiencies are within the reference detection efficiency ranges for G-M pancake detector. Table 7 represents the 
calculated readings in $\mathrm{Bq} / \mathrm{cm}^{2}$ and the percentages of error of the instrument.

Table 7. Calculated Reading $\left(\mathrm{Bq} / \mathrm{cm}^{2}\right)$ and $\%$ of error

\begin{tabular}{ccccccccccc}
\hline $\begin{array}{c}\text { Radio- } \\
\text { Nuclide }\end{array}\left(\begin{array}{c}\text { SER } \\
\left(\mathrm{Bq} / \mathrm{cm}^{2}\right)\end{array}\right.$ & \multicolumn{3}{c}{$\begin{array}{c}\text { Calculated Reading }\left(\mathrm{Bq} / \mathrm{cm}^{2}\right) \\
\left(M e t e r \text { reading X } C_{F}\right)\end{array}$} \\
\hline & & $\begin{array}{c}\text { Left } \\
\text { Hand }\end{array}$ & $\begin{array}{c}\text { Right } \\
\text { Hand }\end{array}$ & $\begin{array}{c}\text { Left } \\
\text { Foot }\end{array}$ & $\begin{array}{c}\text { Right } \\
\text { Foot }\end{array}$ & $\begin{array}{c}\text { Left } \\
\text { Hand }\end{array}$ & $\begin{array}{c}\text { Right } \\
\text { Hand }\end{array}$ & $\begin{array}{c}\text { Left } \\
\text { Foot }\end{array}$ & $\begin{array}{c}\text { Right } \\
\text { Foot }\end{array}$ \\
\hline C-14 & 20 & 22.5 & 22.22 & 22.63 & 22.76 & 12.5 & 11.11 & 13.15 & 13.81 \\
Cl-36 & 19.96 & 20.44 & 20.43 & 20.46 & 20.44 & 2.43 & 2.37 & 2.50 & 2.38 \\
Sr-90 & 18.87 & 19.07 & 19.10 & 19.06 & 19.06 & 1.07 & 1.20 & 1.01 & 1.01 \\
Am-241 & 16.52 & 16.95 & 17.13 & 17.02 & 17.06 & 2.63 & 3.70 & 3.03 & 3.26 \\
\hline
\end{tabular}

The values have been calculated by multiplying measured activities with nuclidespecific calibration factors. Experimental values have been compared with typical surface emission rate values and the results are found to be satisfactory. Figure 3 shows the efficiency of the detectors in the four different zones as a function of beta particle energy. From Table 7 it is clear that the experimental results are approximately within typical values. It turns out that the efficiency is proportional to the maximum beta energy. It can be understood, that the greater the energy of the particle, the more likely it is to penetrate the barriers and reach the active region of the tube to be detected.
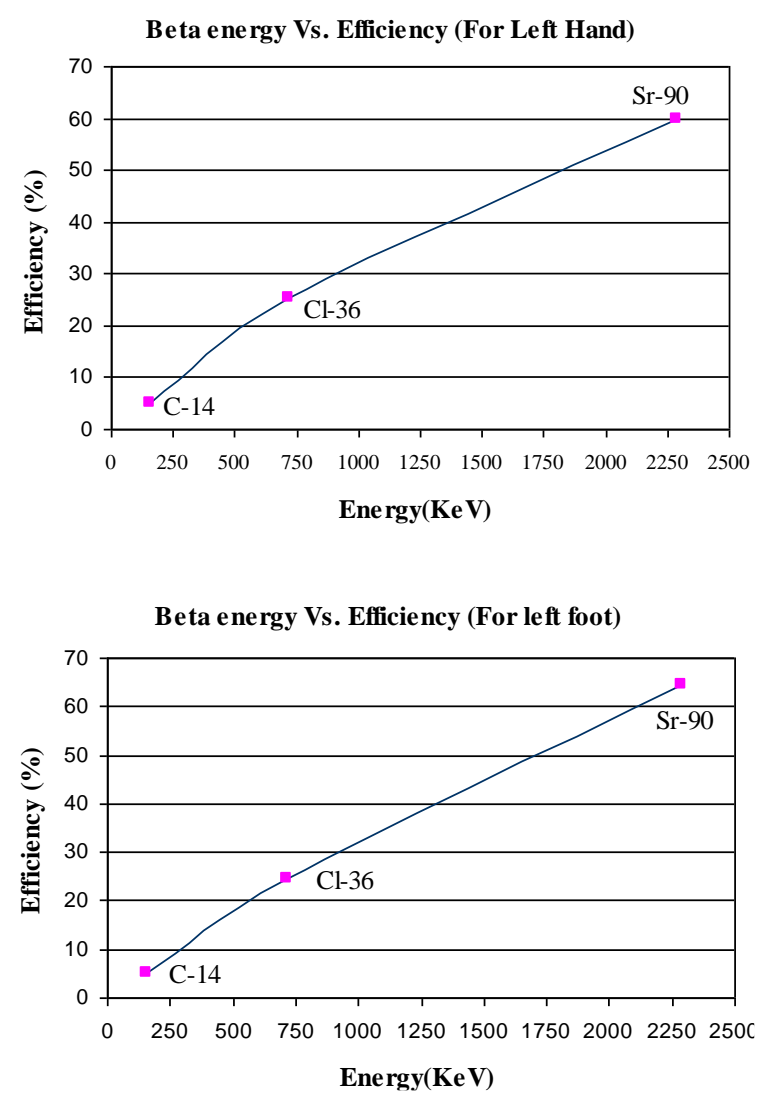

Beta energy Vs.Efficiency (For Right hand)

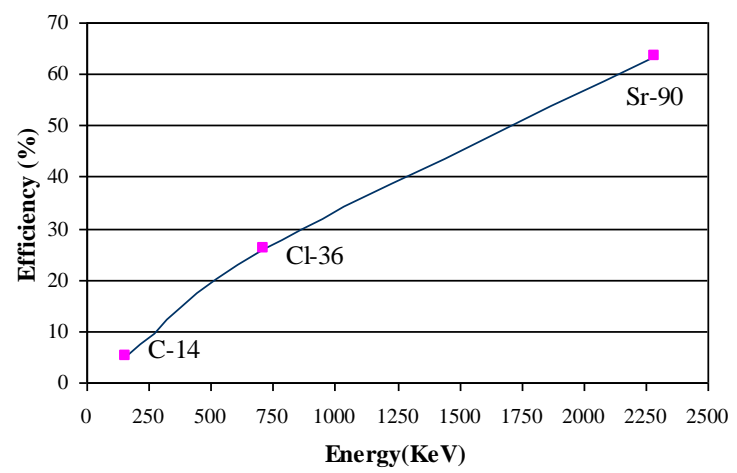

Beta Energy Vs. Efficiency(For Right Foot)

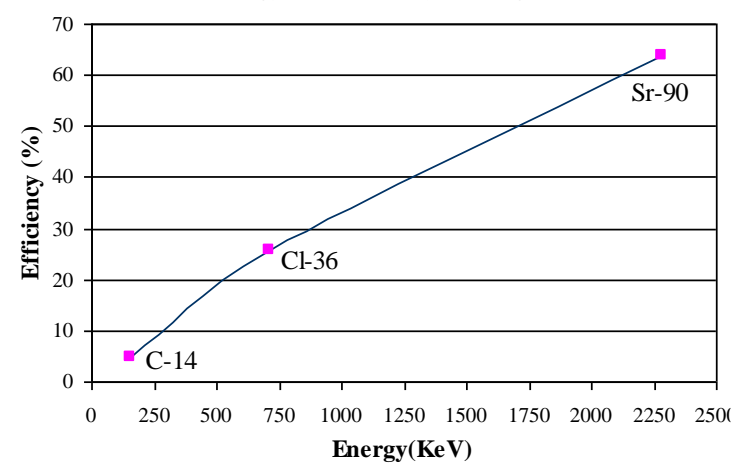

Fig. 3. Beta particle energy verses efficiency of the contamination monitor.

\section{CONCLUSION}

The designed contamination monitor is calibrated electronically to satisfy regulatory requirements. Furthermore a standard calibration has been done by using certified known-activity isotopes. The contamination monitor warns people when the radiation in the area exceeding presettable limits by audiovisual alarm system. Separate readouts are provided on a linear analog panel meter scaled $0-100 \mathrm{~Bq} / \mathrm{cm}^{2}$. The flashing red $L E D$ indicates the location of the contamination, whereas non-contamination detectors are shown by flashing green $L E D$. Electronic linearity, detection efficiency, response to the contamination, calibration factor and percentage of error have been measured and found satisfactory. The background is monitored continuously while the system is unoccupied. This instrument is reliable in operation and its costs less than an imported one.

\section{REFERENCES}

1. Anonymous, MC14528 Dual Monostable Multivibrator, ON Semiconductor [Online], 
http://www.onsemi.com/pub_link/Collateral/ MC14528B-D. PDF. Retrieved in June (2011).

2. R.F. Coughlin, Operational Amplifiers and Linear Integrated Circuits, $4^{\text {th }}$ ed., Prentice Hall of India Private Limited, New Delhi (1994) 53.

3. R. Boylestad, Diode Applications, in: Electronic Devices and Circuit Theory, $5^{\text {th }}$ ed., Prentice-Hall of India private Limited, New Delhi- (1993) 87.

4. C. Lee, The Examination, Testing and Calibration of Portable Radiation Protection Instruments, National Measurement System, Consultation Draft, Measurement Good Practice Guide No. 14 [Online], http://www.npl. co.uk/upload/pdf/gpg14-consultation-draft-feb 2011.pdf. Retrieved in March (2011).

5. Anonymous, Radiation Source Handling Instructions for Reference and Calibration Sources, Technical Data, Eckert \& Ziegler,
Isotope Products Laboratories, 24937 Avenue Tibbitts, Valencia, California 91355, October (2009).

6. Anonymous, Measurement Solutions for Nuclear Safety, Security and the Environment, Pancake and Mica End Window GM Detectors, CANBERRA Industries Inc. [Online], http://www.lip.pt/ patricia/FisicaDaRadiacao/Geige r-Mueller-Detectors-Canberra-sheet.pdf. Retrieved in April (2013).

7. P.R. Steinmeyer, G-M Pancake Detectors: Everything you've wanted to Know, RSO Magazine, Vol. 10, No. 5, pp.9. [Online], http://www.radpro.com/RSO-10-5-PRS.pdf. Retrieved in March (2013).

8. Anonymous, Calibration of Radiation Protection Monitoring Instruments, IAEA Safety Related Publications, Safety Reports Series, No. 16. [Online], http://www-pub.iaea.org/MTCD/pub. iaea.org/MTCD/publications/PDF/P074_scr.pdf, 114-115. Retrieved in January (2000). 